\title{
Survivorship Will Be the Defining Challenge of Critical Care in the 21st Century
}

D istracted by the high mortality rate of critical illness, we tend to overlook the essential fact that most patients survive the intensive care unit (ICU). Every year, millions of patients are discharged from the ICU to face the challenges of critical illness survivorship-the complex burdens and legacies of surviving a potentially fatal disease, often after harsh and painful treatment.

The emerging picture of critical illness survivorship is deeply disturbing. In the year or two after discharge, patients are ravaged. They cannot walk. They cannot think clearly. They suffer from posttraumatic psychiatric syndromes. Their bodies hurt, are disfigured, and refuse to function like they did before. Many intensivists have a file of heartbreaking letters from former patients, grateful to be alive but desperate for help in getting their lives back.

High-quality research (1) has slowly emerged to verify and contextualize these clinical impressions, particularly about medium-term outcomes - the first 12 months after discharge. In this issue, Unroe and colleagues (2) have made a valuable contribution by describing the complexities faced by patients discharged from the ICU after prolonged mechanical ventilation. The authors followed 126 consecutively enrolled patients from ICUs at Duke University, achieving a stunning $100 \%$ follow-up at 1 year. At that time, $56 \%$ of the patients were still alive; however, $84 \%$ were not functionally independent, and $44 \%$ were markedly cognitively impaired. Overall quality of life was poor, and ongoing health care costs were exceedingly high. Particularly revealing is Figure 1, which shows the bewildering array of care transitions these survivors faced as they bounced between hospitals, long-term acute care facilities, and other medical institutions.

It can be frankly overwhelming to face the complexities and human suffering unearthed by Unroe and colleagues as well as other investigators. One way to begin grappling with the needs and hurts of critical illness survivors may be to learn from the experience of cancer survivors (3). Survivors of both critical illness and cancer emerge from a highly technical acute hospitalization, filled with arcane therapies and enigmatic disease processes. Both are discharged alive but face profound existential uncertainties and, often, an alienated relationship with their own bodies. They are disconnected from their primary care physicians and previous support networks (4), and their postdischarge care is complex and often poorly planned. Their loved ones must shoulder a substantial burden, providing home care and succor while also coordinating medical care $(5,6)$.

For more than 20 years, the oncology community has recognized these challenges and made substantial progress toward preventing or ameliorating them. But we need to be clear: Cancer survivorship has improved not just because of heroic efforts by cancer survivors and their physicians, nor as an inevitable result of new cytotoxic therapies. The lives of cancer survivors have gotten better because improving cancer survivorship has been institutionally supported as a goal of research and care. This effort has created a strong infrastructure, with both the National Cancer Institute and the Centers for Disease Control and Prevention establishing cancer survivorship programs. The needs of cancer survivors have prompted an Institute of Medicine report (7). Better care has resulted from specialists working with primary care physicians, nurses, and survivors themselves to develop innovative new programs to meet the needs of survivors-needs defined by a comprehensive research agenda. Perhaps the most important lesson of cancer survivorship that we can apply to critical illness is this: If survivorship is a priority, we can improve the lives of survivors.

Viewing critical illness survivorship through the lens of cancer survivorship reveals several deficits in our current ICU knowledge and practice. For example, some studies of cancer survivorship begin 5 years after diagnosis. In contrast, much of the data collected in critical care survivors, although characterized as long-term outcomes, are actually medium-term outcomes. Recent geriatrics research $(8,9)$ has shown that patients discharged from a general medical service are still recovering functional status up to 18 months later. The most poignant challenges of critical illness survivorship may be those that persist for years after recovery-suggesting that we need much more long-term outcome data at 5 years and beyond (10) and that we need to learn how to improve these outcomes. While we build on recent discoveries in ICU-acquired weakness (11) and cognitive dysfunction (12), it behooves us to consider the likelihood that additional late effects may not show themselves during medium-term follow-up. The research agenda needs to broaden, to encompass not only the risks of mechanical ventilation but also other potential risk factors, such as dysregulated inflammatory cascades, specific organ failures, frequent delirium (13), and mandated bed rest (14). Which of these insults - or in what combinationdrive each of the various long-term problems of critical illness survivors is an open question.

In the ICU, with lives at risk and death so imminent, it is easy to miss opportunities to improve the quality of our patients' lives after the ICU. Working as hard as we must to save patients' lives may leave us feeling that little time remains for other goals (15). And so we immobilize our patients. We catheterize and even paralyze them. Too often, we tranquilize them in the misguided hope that if 
they do not remember the ICU, their critical illness will not scar them.

An alternative is emerging. We can recognize that survivorship care must begin on the first day a patient spends in the ICU. This may mean redesigning basic features of ICU care to place a premium on maintaining patients' physical and cognitive function (16-18). In the past decades, we closed admitting privileges to most ICUs for very good reasons. Now, we may need to open the discharge process, learning how to integrate those professionals who will help in the years-long process of healing from critical illness. We must find new approaches so that patients' ICU experiences are not simply a black box for their primary care physicians. These changes will not be easy, and there will be false starts (19). But others have done as much for their patients, and we can do it for critical illness survivors.

The rapidly growing ranks of critical illness survivors can be powerful partners as we face this defining challenge. Modern cancer care and research would be greatly diminished were it not for the sustained efforts of cancer survivors and those who love them. Critical illness survivors can have the same extraordinary effect, if the right institutions are built to support them. Millions of Americans survive critical illness. Many of those survivors will send their physicians letters full of pain, but also of thanks and of hope. We need to mobilize our combined expertise and creativity while learning from the successes of cancer survivors, to ensure that we can do better for our next patients in the ICU.

Theodore J. Iwashyna, $M D, P h D$

University of Michigan

Ann Arbor, MI

Grant Support: By the National Institutes of Health (grant K08HL091249).

Potential Conflicts of Interest: Disclosures can be viewed at www .acponline.org/authors/icmje/ConflictOfInterestForms.do? msNum $=\mathrm{M} 10$ -1344 .

Requests for Single Reprints: Theodore J. Iwashyna, MD, PhD, Assistant Professor of Internal Medicine, Pulmonary and Critical Care Medicine, 3A23 300 NIB, SPC 5419, 300 North Ingalls Building, Ann Arbor, MI 48109-5419; e-mail, tiwashyn@umich.edu.

Ann Intern Med. 2010;153:204-205.

\section{References}

1. Angus DC, Carlet J, eds. Surviving Intensive Care. New York: Springer Verlag; 2003.

2. Unroe M, Kahn JM, Carson SS, Govert JA, Martinu T, Sathy SJ, et al. One-year trajectories of care and resource utilization for recipients of prolonged mechanical ventilation. A cohort study. Ann Intern Med. 2010;153:167-75.

3. Mullan F. Seasons of survival: reflections of a physician with cancer. N Engl J Med. 1985;313:270-3. [PMID: 4010738]

4. Beckman H. Three degrees of separation. Ann Intern Med. 2009;151:890-1. [PMID: 20008765]

5. Azoulay E, Pochard F, Kentish-Barnes N, Chevret S, Aboab J, Adrie C, et al; FAMIREA Study Group. Risk of post-traumatic stress symptoms in family members of intensive care unit patients. Am J Respir Crit Care Med. 2005;171: 987-94. [PMID: 15665319]

6. Cameron JI, Herridge MS, Tansey CM, McAndrews MP, Cheung AM. Well-being in informal caregivers of survivors of acute respiratory distress syndrome. Crit Care Med. 2006;34:81-6. [PMID: 16374160]

7. Hewitt M, Greenfield S, Stovall E, eds. From cancer patient to cancer survivor: Lost in translation. Washington, DC: National Academies Pr; 2006.

8. Boyd CM, Ricks M, Fried LP, Guralnik JM, Xue QL, Xia J, et al. Functional decline and recovery of activities of daily living in hospitalized, disabled older women: the Women's Health and Aging Study I. J Am Geriatr Soc. 2009;57: 1757-66. [PMID: 19694869]

9. Boyd CM, Landefeld CS, Counsell SR, Palmer RM, Fortinsky RH, Kresevic $\mathrm{D}$, et al. Recovery of activities of daily living in older adults after hospitalization for acute medical illness. J Am Geriatr Soc. 2008;56:2171-9. [PMID: 19093915] 10. Cuthbertson BH, Roughton S, Jenkinson D, Maclennan G, Vale L. Quality of life in the five years after intensive care: a cohort study. Crit Care. 2010;14:R6. [PMID: 20089197]

11. Schweickert WD, Hall J. ICU-acquired weakness. Chest. 2007;131:1541-9. [PMID: 17494803]

12. Hopkins RO, Jackson JC. Short- and long-term cognitive outcomes in intensive care unit survivors. Clin Chest Med. 2009;30:143-53. [PMID: 19186286]

13. Pun BT, Ely EW. The importance of diagnosing and managing ICU delirium. Chest. 2007;132:624-36. [PMID: 17699134]

14. Needham DM. Mobilizing patients in the intensive care unit: improving neuromuscular weakness and physical function. JAMA. 2008;300:1685-90. [PMID: 18840842]

15. Fried TR, Bradley EH, Towle VR, Allore H. Understanding the treatment preferences of seriously ill patients. N Engl J Med. 2002;346:1061-6. [PMID: 11932474]

16. Hopkins RO, Spuhler VJ, Thomsen GE. Transforming ICU culture to facilitate early mobility. Crit Care Clin. 2007;23:81-96. [PMID: 17307118]

17. Schweickert WD, Pohlman MC, Pohlman AS, Nigos C, Pawlik AJ, Esbrook CL, et al. Early physical and occupational therapy in mechanically ventilated, critically ill patients: a randomised controlled trial. Lancet. 2009;373: 1874-82. [PMID: 19446324]

18. Girard TD, Kress JP, Fuchs BD, Thomason JW, Schweickert WD, Pun BT, et al. Efficacy and safety of a paired sedation and ventilator weaning protocol for mechanically ventilated patients in intensive care (Awakening and Breathing Controlled trial): a randomised controlled trial. Lancet. 2008;371:126-34. [PMID: 18191684]

19. Cuthbertson BH, Rattray J, Campbell MK, Gager M, Roughton S, Smith A, et al; PRaCTICaL study group. The PRaCTICaL study of nurse led, intensive care follow-up programmes for improving long term outcomes from critical illness: a pragmatic randomised controlled trial. BMJ. 2009;339:b3723. [PMID: 19837741] 